\title{
Farklı üzüm tür ve çeşitlerinin melezlenmesi ile elde edilen melez genotiplerin canlı tohum oranlarının belirlenmesi
}

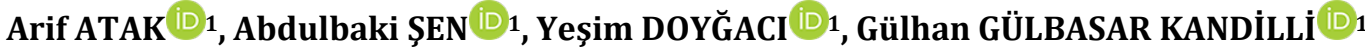

${ }^{1}$ Atatürk Bahçe Kültürleri Merkez Araştırma Enstitüsü Müdürlüğü, YALOVA

Alınış tarihi: 1 Ağustos 2019, Kabul tarihi: 25 Kasım 2019

Sorumlu yazar: Arif ATAK, e-posta: arif.atak@tarimorman.gov.tr

Öz

Bağcılıkta melezleme ıslahı çalışmaları yeni çeşit elde etmek amaciyla uzun yllardan beri yaygın olarak kullanılmaktadır. Melezleme ıslahı çalışmalarında melez çekirdeklerin canlılık oranları değişkenlik gösterebilmektedir. Özellikle seçilen ana ve baba çeşitlere bağlı olarak melezleme ile elde edilen çekirdeklerin canlılık oranlarının farklılık gösterebildiği bilinmektedir. Bu çalışmada 15 farklı üzüm çeșidi ile 24 farklı kombinasyonda melezleme yapılarak elde edilen melez çekirdeklerin canlılık oranları incelenmiştir. 15 farklı üzüm çeşidinden 9 çekirdeksiz üzüm çeşidi baba ve 6 üzüm çeşidi ana olarak kullanılmıștır. Baba olarak kullanılan tüm çeşitler Vitis vinifera türüne ait çeşitlerden oluşurken ana olarak kullanılan çeşitlerin 4 tanesi $V$. vinifera, 1 tanesi türler arası melez ve 1 tanesi de Vitis labrusca türüne ait çeșitten oluşmuştur. Çalışma sonucunda hem canlılık oranı hem de canlı çekirdek sayısı dikkate alındığında Red Globe'un ana olarak kullanıldığı kombinasyonlar öne çıkarken, Kyoho çeșidinin ana olarak kullanıldı ̆̆ kombinasyonlarda gerek canlı çekirdek sayısı gerekse de oranı bakımından kayda değer sonuçlar alınamamıştır.

Anahtar kelimeler: Emaskülasyon, farklı türler, kombinasyon, canlılık, çekirdek

Determination of live seed rates of hybrid genotypes obtained by hybridization of different grape species and cultivars

\footnotetext{
Abstract

Breeding studies in viticulture have been widely used for many years in order to obtain new cultivars.
}

In crossbreeding studies, viability rates of hybrid seeds may vary. It is known that the viability of the seeds obtained by crossbreeding may differ especially depending on the selected parents as the mother and pollinator father cultivars. In this study, the viability of hybrid seeds obtained by crossbreeding in 15 different grape cultivars and 24 different combinations were evaluated. 9 seedless grape cultivars used as father-parents and 6 grape cultivars also used for the mother-parents. All cultivars used as father-parents composed of cultivars of Vitis vinifera species whereas the cultivars used as mother-parents belong to different species. Four of them were composed of V. vinifera, one of them were inter-species hybrid, and one of them belonged to the Vitis labrusca. As a result of the study, both the vitality rate and the number of live seeds were taken into consideration; the best combination obtained by Red Globe used as the mother-parent, while no significant results were obtained in terms of both the number and ratio of the live seed of Kyoho cultivars which used as mother parent in combinations.

Key words: Emasculation, different species, combination, vitality, seed

\section{Giriș}

Türkiye bağcllık için dünyanın en elverişli iklim kuşaklarından birisi üzerinde bulunur ve aynı zamanda asmanın gen merkezleri arasında yer alır. Ülkemiz oldukça eski ve köklü bir bağcıllk kültürüne sahip olup dünyanın önde gelen üzüm üreticileri arasındadır (Çelik, 1998). Bağcılık tek başına dünya ekonomisine önemli derecede katkıda 
bulunmaktadır (Zohary and. Hoph, 2000). Son yıllarda dünya pazarlarında özellikle sofralık olarak tüketilen üzüm çeşitlerinin çok hızla değiştiği görülmektedir. $\mathrm{Bu}$ nedenle iç ve dış pazarların aradığı kalitede yeni üzüm çeşitlerinin geliştirilmesine yönelik ıslah çalışmaları devam etmektedir (Uysal ve ark., 2016).

Farklı çeşit veya türlerde bulunan iki ve daha fazla karakterin tek bir bireyde kombine edilmesi suretiyle yeni üzüm çeșitleri ve asma anaçlarının elde edilmesi ya da bazı uygun olmayan özelliklerin düzeltilmesi melezleme ıslahı çalıșmalarıyla mümkün olmaktadır. Bu yöntemle elde edilen asma anaçlarından başka, doğal populasyon içinden seçilmiş üzüm çeşitlerinin kendi aralarında bilinçli ve sistemli olarak melezlenmeleri yoluyla Cardinal, Perlette, İtalya, Ruby Seedless, Queen, Perle de Csaba gibi üstün özellikleri olan ve geniş alanlarda üretimi yapılan birçok üzüm çeşidi elde edilmiştir (Anonim, 1982; Gülcan ve İlter, 1975).

Taze olarak tüketilen sofralık üzümlerde çekirdeksizlik aranan bir özelliktir. Bu nedenle son yıllarda özellikle çekirdeksiz üzüm ıslahı konusunda farklı ülkelerden araștırmacılar yoğun biçimde çalışmaktadır. Bu çalışmalarda özellikle iri taneli, çekirdeksiz ve farklı zamanlarda olgunlaşan üzüm çeşitleri elde edilmeye çalışılmıştır. Gerek iç piyasada gerekse dünya piyasalarında çekirdeksiz sofralık yaş üzüm talebi yıldan yıla artış göstermektedir. Ayrıca son yıllarda hastalıklar konusunda oldukça hassas olan çekirdeksiz üzüm çeşitleri yerine daha dayanıklı olan yeni çekirdeksiz üzüm çeşitleri de elde edilmiştir. Çekirdeksiz üzüm ıslahında araştırmacılar genel olarak 2 farklı yöntem kullanmışlardır. İlk yöntemde tozlayıcı (baba) olarak çekirdeksiz çeşit ve ana olarak çekirdekli çeşitler kullanılırken, İkinci yöntemde iki çekirdeksiz çeşidin melezlenmesini takiben embriyo oluşumunun belli bir safhasında doku kültüründe yapay besi ortamında embriyoların gelişimlerini sağlıklı olarak tamamlamaları için embriyo kurtarma tekniği kullanılmaktadır (Perl et al., 2000).

Üzüm çeşitlerinde iyi bir tane tutumu kendine veya yabancı tozlanma ve onu takiben de döllenme sonucunda oluşmaktadır. Genel bir kural olarak tane tutumu için erselik çiçekli asmalarda kendine, fonksiyonel dişi çiçekli asmalarda ise yabancı tozlanma ve döllenme esastır (Mullins et al., 1992; Marasalı ve Ergül, 1997). Tozlamanın tane tutumunun yanı sıra çekirdek gelişimi üzerinde de etkileri olduğu bilinmektedir. Bu nedenle tozlama şekli, tekniği, çiçek tozu kalitesi ve çeşide bağlı olarak elde edilen melez çekirdeklerin gelişimleri ve canlılık oranları farklılık gösterebilmektedir. Bununla birlikte, yabancı tozlanma ve döllenmenin mümkün olduğu erselik çiçekli asmalarda, tozlamada kullanılan polen kaynağına bağlı olarak meyve tutumunun farklı oranlarda gerçekleştiğini gösteren araştırma sonuçları yaygındır (Sabır, 2015).

Melezleme ile oluşacak genetik varyasyon sslah çalışmalarının başarısında son derece etkilidir. $\mathrm{Bu}$ nedenle ebeveynlerin gerek coğrafi orijin ve gerekse ampelografik özellikler bakımından birbirinden farklı olmaları istenmektedir. Ayrıca ebeveynlerin döllenme biyolojisine ilişkin özellikleri hem melezleme ıslahı çalışmalarında hem de üzüm yetiştiriciliğinde verim ve kalitenin arttırılmasında önemli rol oynar. Çeşitli üzüm genotipleri üzerinde yürütülen araştırılmalarda tozlayıcı çeşidin ana çeşide ait tane ve çekirdek özelliklerin önemli derecede etkilediği kaydedilmiştir. Buna göre tozlayıcı çeşitler üzüm verim ve kalitesinde önemli rolleri olduğu bilinmektedir. Bu sebeple melez kombinasyonları seçerken bu hususların mutlaka dikkate alınması gerekir (Şahin, 2016).

Farklı bitki türleri çiçeklenme ve ardından tozlanmayı takiben gelişmeleri sırasında pek çok faktöre bağlı olarak tohum veya çekirdek oluşumu sirasinda istenen canlllı seviyesine ulaşamayabilirler. Bu faktörler arasında genetik önemli bir yer tutar. $\mathrm{Bu}$ sebeple kullanılan ebeveynlere bağlı olarak canlılık oranlarında farklılıklar görülebilir. $\mathrm{Bu}$ durumun özellikle embriyo gelişimi ile ilgili olduğu düşünülür (Karakurt ve ark., 2010). Bazen de birçok meyve türünün olgunlaşmış sağlam tohumları yeterli gelişme göstermesine rağmen sıcaklık, nem, oksijen ve ışık gibi çevre koşullarının da uygun olmasıhalinde bile çimlenmezler. Bu olaya dormansi denir ve hemen hemen tüm llıman iklim meyve türlerinin tohumlarında görülür (Çetinbaş ve Koyuncu, 2005; Demirkaya, 2006, Akkurt et al., 2013). Üzüm tane ve çekirdeklerinin gelişimi üç safhada gerçekleşmektedir. İlk safhada meyve tutumu için hızlı bir hücre bölünmesi ve genişlemesi gerçekleşirken ikinci safhada daha yavaş bir büyüme görülür. Son safhada ise olgunlaşma gerçekleşir. Çekirdek gelişiminde meyve tutumundan olgunluğa kadar benzer üç safha görülür. Çekirdek olușumunun özellikle ikinci safhasında rezerv materyalleri birikimi olur. Çekirdek su içeriğindeki artışla bağlantılı olarak hücre genişlemeleri görülür. 
Çekirdeğin su içeriği ile büyüklüğü arasında yakın bir ilişki vardır. Bu safhada hücre sayısı değişmezken irilik daha çok hücre hacmiyle ilişkilidir. Üçüncü safhada rezerv materyalleri birikimi yavașlar ve fizyolojik olgunluk durur. Üzüm çekirdeklerinde canlılık ile bu gelişim evreleri arasında çok yakın bir ilişki olduğu düşünülmektedir (Egli, 1998). Çekirdek gelişimi ve meyve olgunlaşması çeşitlere ve çekirdek içindeki polifenollere görede değişiklik göstermektedir. Meyve olgunlaşması sırasında üzüm çekirdeğinin yapısı ile polifenol değișimlerinin hücre kimyası tam bilinmemektedir (Kennedy et al., 2000; Downey et al., 2003). İyi bir lignin dokusuna sahip olan çekirdeklerin olgunlaşma sırasında mikroskopik çalışması çok zor olduğu için bu konuyla ilgili oldukça sınırlı sayıda çalışma bulunmaktadır (Cadot et al., 2006).

Bu çalışmada 15 farklı üzüm çeșidi ile 24 farklı kombinasyonda melezleme yaplarak elde edilen melez çekirdeklerin canlılık oranlarının çeșide bağlı olarak gösterdiği değișimler belirlenmeye çalıșılmıștır.

\section{Materyal ve Yöntem}

Bu çalışma Yalova Atatürk Bahçe Kültürleri Merkez Araştırma Enstitüsü araştırma ve uygulama bağı ile Bağcllı laboratuvarlarında yürütülmüștür. Çalışmada farklı türlere ait 15 farklı üzüm çeşidi ve bunlardan oluşturulan 24 farklı kombinasyon kullanılmıştır (Çizelge 1 ve 2). Çalışmada Kober 5 BB anacı üzerine aşılı 15 yaşlı asma omcaları üzerinde melezlemeler yapılmıștır. Çalıșmalarda aşağıda maddeler halinde açıklamaları verilen klasik melezleme ıslahı tekniği kullanılmıștır (Șekil 1).

Emaskulasyon: Çiçekler açmadan önce çiçek tomurcuğu üzerinde bulunan korolla dişi organa zarar vermeden erkek organlarla birlikte çıkarılmıştır. Emaskulasyon işlemi yaparken salkımda hiçbir çiçeğin açmamış olmasına özen gösterilmiştir. Her bir salkımda en az 100 adet çiçek olacak şekilde emaskulasyon işlemi bir pens yardımıyla yapılmıştır. Emaskulasyon işlemi tamamlanan salkımlara çiçek tozlarını ve suyu geçirmeyen havayı ise çok sınırlı oranda geçiren özel keseler takılmıștır. Çalıșmada ana olarak kullanılan Beyaz Çavuş çiçek tozları steril (kendine kısır) olması sebebiyle bir emaskulasyona tabi tutulmadan direk keselenmişlerdir. Beyaz Çavuş çeşidi dışında tüm kombinasyonlarda emaskulasyon uygulaması ve ardından tozlama yapılarak melez üzüm çekirdekleri elde edilmiștir.
Çizelge 1. Çalışmada kullanılan çeşitlerin türü ve bazı tane özellikleri

\begin{tabular}{|c|c|c|c|c|}
\hline Çeşit Adı & Tür & $\begin{array}{l}\text { Tane } \\
\text { rengi }\end{array}$ & $\begin{array}{l}\text { Tane } \\
\text { iriliği }\end{array}$ & Çekirdeklilik \\
\hline $\begin{array}{l}\text { Kishmish } \\
\text { Vatkana }\end{array}$ & $\begin{array}{c}\text { Vitis } \\
\text { vinifera }\end{array}$ & $\begin{array}{c}\text { Koyu } \\
\text { Pembe }\end{array}$ & Küçük & Yok \\
\hline $\begin{array}{l}\text { Crimson } \\
\text { Seedless }\end{array}$ & $\begin{array}{c}\text { Vitis } \\
\text { vinifera }\end{array}$ & $\begin{array}{l}\text { Koyu } \\
\text { Pembe }\end{array}$ & Orta & Yok \\
\hline $\begin{array}{l}\text { Superior } \\
\text { Seedless }\end{array}$ & $\begin{array}{c}\text { Vitis } \\
\text { vinifera }\end{array}$ & Beyaz & Orta & Yok \\
\hline $\begin{array}{c}\text { Autumn } \\
\text { Royal }\end{array}$ & $\begin{array}{c}\text { Vitis } \\
\text { vinifera }\end{array}$ & Siyah & Orta & Yok \\
\hline $\begin{array}{c}\text { Yalova } \\
\text { Çekirdeksizi }\end{array}$ & $\begin{array}{c}\text { Vitis } \\
\text { vinifera }\end{array}$ & Beyaz & Orta & Yok \\
\hline & $\begin{array}{c}\text { Vitis } \\
\text { vinifera }\end{array}$ & Beyaz & Küçük & Yok \\
\hline $\begin{array}{c}\text { Samancl } \\
\text { Cekirdeksizi }\end{array}$ & $\begin{array}{c}\text { Vitis } \\
\text { vinifera }\end{array}$ & Beyaz & Küçük & Yok \\
\hline $\begin{array}{l}\text { Fantasy } \\
\text { Seedless }\end{array}$ & $\begin{array}{c}\text { Vitis } \\
\text { vinifera }\end{array}$ & Siyah & Orta & Yok \\
\hline $\begin{array}{c}\text { Bronx } \\
\text { seedless }\end{array}$ & $\begin{array}{l}\text { Türler } \\
\text { arası } \\
\text { melez }\end{array}$ & Kırmızı & Küçük & Yok \\
\hline Red Globe & $\begin{array}{c}\text { Vitis } \\
\text { vinifera }\end{array}$ & $\begin{array}{l}\text { Koyu } \\
\text { Pembe }\end{array}$ & $\begin{array}{c}\text { Çok } \\
\text { Büyük }\end{array}$ & Çekirdekli \\
\hline $\begin{array}{l}\text { Köfteci } \\
\text { üzümü }\end{array}$ & $\begin{array}{c}\text { Vitis } \\
\text { labrusca }\end{array}$ & Siyah & Orta & Çekirdekli \\
\hline Kyoho & $\begin{array}{c}\text { Türler } \\
\text { arası } \\
\text { melez }\end{array}$ & Siyah & Büyük & Çekirdekli \\
\hline Beyaz Çavuş & $\begin{array}{c}\text { Vitis } \\
\text { vinifera }\end{array}$ & Beyaz & Orta & Çekirdekli \\
\hline $\begin{array}{l}\text { Yalova } \\
\text { Beyazı }\end{array}$ & $\begin{array}{c}\text { Vitis } \\
\text { vinifera }\end{array}$ & Beyaz & Büyük & Çekirdekli \\
\hline Atasarısı & $\begin{array}{c}\text { Vitis } \\
\text { vinifera }\end{array}$ & Beyaz & $\begin{array}{c}\text { Çok } \\
\text { Büyük }\end{array}$ & Çekirdekli \\
\hline
\end{tabular}

Çiçek tozlarının elde edilmesi: Melezlemelerde baba olarak kullanılan çekirdeksiz üzüm çeşitlerine ait çiçek tozları şu şekilde temin edilmiştir; çiçek tozları alınacak olan çeşit tam çiçeklenme dönemine girdiği zaman bu çeşidin salkımları kuru plastik poşetler içine toplanmıştır. Daha sonra vakit geçirmeden laboratuvara getirilerek burada bir elekten geçirilerek diğer bileşenlerinden ayrılmışlardır. Çiçek tozları buradan içinde nem alıcı silika jel bulunan kavanozlara alınmışlardır. Çekirdeksiz çeşitlere ait çiçek tozları kullanılana kadar $+4{ }^{\circ} \mathrm{C}$ 'de muhafaza edilmișlerdir.

Tozlama: Emaskulasyon ișlemi yapılarak keselere alınan salkımlar, sık sık kontrol edilerek dișicik tepesinde şekerli sıvı görüldüğünde tozlayıcı çekirdeksiz çeșitlerden alınan çiçek tozlarıyla tozlanmışlardır. Dişicik tepesi üzerindeki şekerli sıvı günün çok güneşli sıcak saatlerinde kaybolması sebebiyle tozlama işleminin sabah erken saatlerde yapılmasına dikkat edilmiştir. 


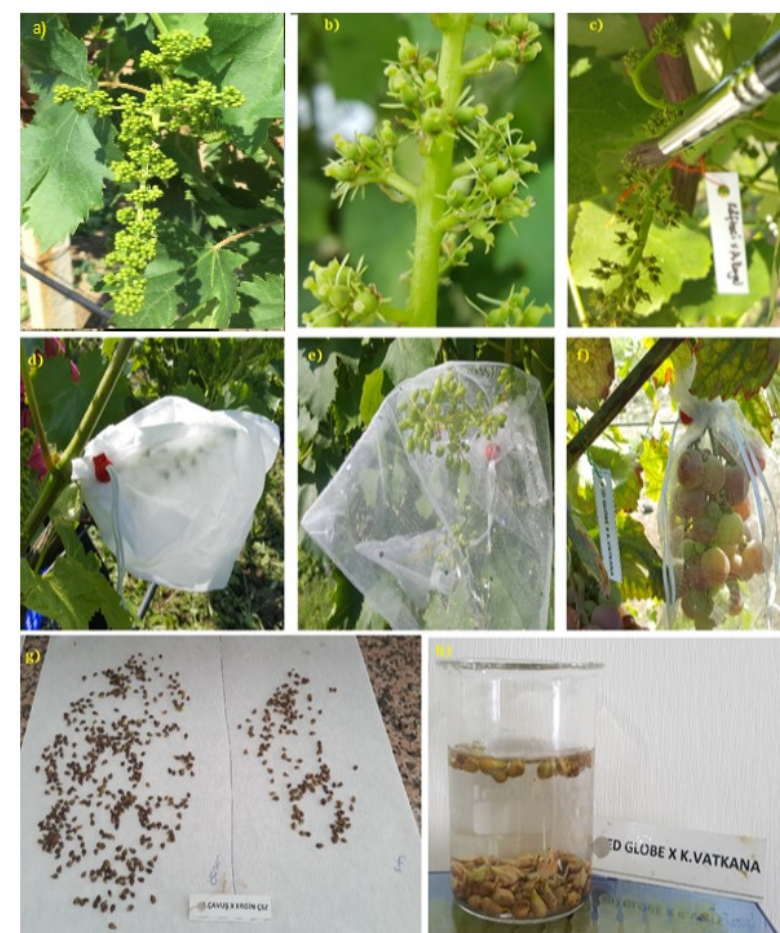

Şekil 1. Melezleme çalışmalarının tüm aşamalarına ait bazı resimler

a) Emaskulasyon öncesi salkım, b) Emaskulasyonu yapılmış salkım, c) Tozlama, d) Emaskule edilen salkımların keselenmesi, e) Tane tutumundan sonra keselerin daha iyi hava alan keselerle değiştirilmesi, f) Hasat zamanı, g) Melez çekirdeklerin çıkartılıp kurutulması, h) Canlılık testi

Tozlamada baba çeşidin çiçek tozları ana çeşidin dişicik tepesine önece firça ile sürülmüş daha sonra ise içinde çiçektozu bulunan naylon torba tozlanacak salkıma geçirilerek çiçek tozları üzerine silkelenmiştir. $\mathrm{Bu}$ işlem çiçeklenme devresi içerisinde gün aşırı birkaç defa tekrar edilmiştir. Tozlama bittikten sonra salkımlar tekrar torbalanarak ve üzerine ana ve baba çeșidin isimleri ile tozlama tarihleri yazılı olan etiketler takılmıștır. Melez salkımlar keseli olarak kombinasyona bağlı olarak 2-3 hafta bekletildikten sonra melezleme keseleri çıkarılmış bunun yerine file keseler takılmıştır. Özellikle kuş zararına karşı bu yöntem izlenmiş ve hasada kadar düzenli olarak omcaların bakım ve ilaçlamaları yapılmıştır.

Hasat: Kombinasyona bağlı olarak Ağustos ayının 3. haftası ile Eylül ayının son haftasına kadar hasat işlemleri yapılmıştır. Hasat sırasında çeşitlerin en az \%18 Brix değerinde ve kendine has rengi almış olmalarına dikkat edilmiștir. Hasat edilen melez üzümlere ait salkımlar laboratuvara getirilerek salkım iskeletinden ayrılmış ve üzüm tanelerinin içindeki çekirdekler bir süzgeç yardımıyla çıkartılmıștır. Çıkartılan çekirdekler saf suyla yıkanarak diğer bileșenlerinden ayrılmaları sağlanmış ve daha sonra birkaç gün kurutma kâğıdında kurumaya bırakılmışlardır.

Canlılık testi: Kuruyan ve diğer bileşenlerinden ayrılan melez üzüm çekirdekleri saf su ile dolu olan beher kaplar içerisine konulmuştur. Bu kaplar içine konan melez üzüm çekirdekleri kombinasyonlarına bağlı olarak farklı oranda suya battıkları ve bazılarının da suyun üstünde yüzdükleri görülmüştür. Suya batan ve yüzen üzüm çekirdeklerinin sayıları belirlendikten sonra yüzde canlılık oranları hesaplanmıștır. Suda batanlar canlı kabul edilirken yüzenler ise nispeten canlı olmayan çekirdekler olarak kabul edilmişlerdir.

İstatistik analizler: Araştırma sonuçlarının değerlendirilmesinde ve özellikle kombinasyonlara bağlı olarak elde edilen canlı çekirdek sayısına doğru biçimde ulaşmak amacıyla canlılık oranı esas alınmıştır. \% Canlılık Oranı = (100 X canlı çekirdek) / (canlı çekirdek + cansız çekirdek) formülüne göre belirlenmiştir. Canlılık oranı için varyans analizi uygulanmış, farklılıklar \%5 güven aralığında ( $\mathrm{P}$ <0.05) belirlenmeye çalışılmıştır. Elde edilen verilerin karşılaştırılmasında LSD (Least Significant Difference: Asgari Önemli Fark) çoklu karşılaştırma testi uygulanmıştır. İstatistiksel analizler için, JMP 5.0.1 (SAS Institute, (2007) istatistik paket programı kullanılmıştır.

\section{Bulgular ve Tartışma}

Melezleme ıslahı çalışmalarında bu çalışmada olduğu gibi seçilen ana ve baba ebeveynlere göre elde edilen melez tohumların canlılık oranları değişkenlik gösterebilmektedir. Bunun dışında yapılan emaskulasyon, alınan çiçek tozunun canlılığı, çiçek tozunun alınma zamanı, suni tozlamanın yapılma zamanı, bitkinin sağlık durumu gibi faktörlerde melez tohumlarm canlılı oranlarını etkileyebilmektedir (Altıntoprak ve Ağaoğlu, 1999).

Çizelge 2'de 24 farklı kombinasyonun kullanılması sonucunda elde edilen sonuçlar ve Çizelge 3 ' te ise ebeveyn olarak kullanılan çeşitlerin farklı kombinasyonlarından elde edilen melez bireylerin canlılık ortalamaları verilmiştir. Sonuçlara bakıldığında özellikle ana olarak kullanılan çeşitlerin melez tohumların canlılık oranlarını önemli oranda etkilediği görülmektedir. Baba olarak kullanılan tozlayıcı çekirdeksiz çeşitlerinde canlılıkta etkili olmasına karşlık ana olarak seçilen çeşitler kadar canlılık oranları üzerinde etkili olmadığı 
görülmektedir. Türler arası melez olan Kyoho çeșidinin ana olarak kullanıldığı kombinasyonlar çalışma genelinde istenmeyen sonuçların alındı̆̆ı grubu olușturmuștur. Bu durumda özellikle Kyoho çeșidinin $4 \mathrm{n}$ kromozom sayısının etkili olduğu düşünülmektedir. Wakana et al. (2003) yaptıkları benzer bir çalışmada $4 \mathrm{n}$ olan Kyoho çeșidi ile $2 \mathrm{n}$ çeşitlerini melezlemiş ve çalışma sonucunda çok düşük canlı tohum elde ettiklerini bildirmișlerdir. Bunun sebebi olarak ta $3 \mathrm{n}$ olan melez tohumlarda endosperm dejenerasyonu sebebiyle aborsiyonlar olduğu bu sebeple bunların çimlenip yeni bir birey oluşturmalarının çok zor olduğunu bildirmişlerdir. Benzer bir çalışma Tian et al. (2008) tarafından farklı türlere mensup ve hastalıklara dayanıklı olan Vitis çeşitleri ile yürütülmüştür. Bu çalışmada da türler arası melezler ile elde edilen melez tohumların canlılık ve çimlenme oranlarının oldukça düşük düzeyde kaldığı bildirilmiştir. Hatta embriyo kurtarma yöntemiyle bile oldukça sınırlı sayıda canlı birey elde edilebildiği bildirilmiştir. Orhan Özalp ve Ergönül (2013) de tetraploid çeşitlerle melezleme çalışmalarında elde edilen melez genotiplerin canlılık oranlarının dipliod olanlara göre daha düșük olduğunu bildirmişlerdir.

Çok iri taneli olan Atasarısı çeşidinin ana olarak kullanıldığı kombinasyonlara baktığımızda ise farklı sonuçlar alındığı görülmektedir. Autumn Royal ile tozlananlarda hiç canlı tohum elde edilemezken, Yalova Cekirdeksizi ile tozlananlarda ise \%43 oranında canlılık olduğu belirlenmiștir. En iyi sonuçlar Crimson Seedless (\%85) ve Kishmish Vatkana (\%80) ile tozlananlardan elde edilmiştir. Atasarısı çeşidi külleme ve Botrytis hastalıkları yönünden oldukça hassas bir çeşittir. Sezon boyunca mantari hastalıklar yönünden yeterli ilaçlama yapılmasına rağmen çeşidin bu hassasiyetinin tohumların canlılıklarını da etkilemiş olabileceği düşünülmektedir. Karataş ve Ağaoğlu (2007) yaptıkları bir çalışmada Atasarısı çeşidini ana olarak kullanıp Kalecik Karası çeşidi ile melezlemişler ve sonuçta \%50'nin altında sonuç elde etmişlerdir. Ayrıca serbest tozlama ile daha yüksek bir oran elde ettiklerini bildirmişlerdir. Araştırmacılar bunun melezleme sonucu ortaya çıkan yeni genetik yapıdan ve emaskulasyon stresinden kaynaklandığını bildirmișlerdir. Benzer bir sonuç ise hastalıklar yönünden hassas bir diğer çeșit olan Yalova Beyazının ana olarak kullanıldığı kombinasyonlarda görülmüştür. $\mathrm{Bu}$ çeşitle yapılan melezlemelerde özellikle elde edilen çekirdek sayısının Atasarısı çeşidinden elde edilenler gibi çok az sayıda olduğu görülmektedir. Bu durumun da emaskulasyon stresi ile ilgili olabileceği düşünülmektedir.

V.labrusca türüne ait olduğu düșünülen Köfteci üzümü özelikle mantari hastalıklara dayanıklılığı nedeniyle seçilmiş ve çalışmada 8 farklı çekirdeksiz çeşidin çiçek tozları ile tozlanmıștır. V.labrusca türüne ait çeşitlerin çiçeklenme zamanı özellikle V.vinifera çeșitlerine göre daha erken olduğu için mutlaka tozlayıcı çeşitlerin çiçek tozlarının bir önceki seneden veya o yll içinde daha sıcak bölgelerden temin edilmesi gerekmektedir. $\mathrm{Bu}$ çeşit/genotip ile yapılan melezleme kombinasyonları incelendiğinde tozlayıcı olarak kullanılan baba çeşide bağlı olarak \%10 ile \%82 arasında değişen oranlarda canlılık elde edildiği görülmektedir. $\mathrm{Bu}$ kombinasyonda da özelikle Autumn Royal ile yapılan tozlamalardan oldukça düşük (\%10) sonuç alındığı görülürken Samancı Çekirdeksizi ile yapılan tozlamalarda ise en yüksek (\%82) canlılık oranına ulaşılmıştır. V.labrusca türüne ait çeşitlerin diğer türlerle başarıyla melezlenmesi ve yüksek canllık oranına sahip melezlerin elde edilmesi çok önemlidir. Çünkü son yıllarda ıslah çalışmalarında bu türe ait olan çeşitler hastalıklara dayanıklılı̆̆l, kendine has aroması ve yüksek fenolik içerikleri sebebiyle yeni sofralık üzüm çeşitlerinin geliştirilmesinde özellikle Amerika ve Uzak Doğu'da daha çok kullanılmaya bașlanmışlardır (Lloreda De la Fuente, 2018). Erkek çiçek tozlarının kısır olduğu ve fonksiyonel dişi çiçek yapısına sahip olduğu bilinen Beyaz Çavuş çeşidi ile yapılan melezleme çalışmalarında herhangi bir emaskulasyon uygulaması yapılmamıștır. Bu çeșit ile 5 farklı çekirdeksiz çeșidin melezlenmesi sonucunda \%6 ile \%54 arasında değișen oranlarda canllık elde edilmiștir. En düșük canlılık diğer çeșitlerden elde edilen sonuçlarla benzer şekilde Autumn Royal çeşidinden elde edilirken en yüksek oran ise Kishmish Vatkana çeşidi ile tozlanan salkımlardan elde edilmiştir. Dardeniz ve ark.(2011) çalışmamızdan elde edilen sonuçlar ile benzer biçimde Çavuş üzüm çeşidinin farklı tozlayıcılar ile tozlanması neticesinde elde edilen tanelerin iriliği ve sayısında farklılıklar olduğunu bildirmişlerdir. $\mathrm{Bu}$ kombinasyonlarda Kishmish Vatkana çeşidinin tozlayıcı olarak kullanıldığı kombinasyondan $\% 85$ ve Crimson Seedless çeşidinin tozlayıcı olarak kullanıldığı kombinasyonda ise \%84 oranında melez çekirdeklerde canlılık oranı tespit edilmiştir. Li et al. (2013) yaptıkları çalışmada da bizim çalışmamızdaki 
sonuçlara benzer şekilde Red Globe çeşidinin kullanıldığı melezleme kombinasyonlarında diğerlerine göre daha iyi sonuçlar alındığını bildirmişlerdir. Farklı tozlayıcı çeşitlerden elde edilen değerlerin ortalamaları incelendiğinde özellikle Autumn Royal çeşidinin oldukça düşük oranda canlılık gösteren melez genotipler verdiği görülmüştür. En iyi sonuç ise sırasıyla Fantasy Seedless, Samancı Çekirdeksizi ve Kishmish Vatkana çeşitlerinden elde edilmiştir. Ana olarak kullanılan çeşitlerin ortalamalarına bakıldığında ise en iyi sonuç Red Globe çeşidinin yer aldığı kombinasyonlardan elde edilmiş ve onu Atasarısı ve Yalova Beyazı çeşitleri izlemesine karşılı bu çeşitlerin yer aldığı kombinasyonlardan elde edilen melez genotip sayısının oldukça sınırlı olduğu görülmüştür (Çizelge 3).

Çizelge 2. Melezleme yapılan kombinasyonlara ait salkım ve çekirdek sayıları ile \% canlılık oranları

\begin{tabular}{|c|c|c|c|c|c|c|c|c|}
\hline \multirow{2}{*}{$\begin{array}{l}\text { Kom. } \\
\text { No }\end{array}$} & \multirow[b]{2}{*}{$\begin{array}{l}\text { Dişi (Ana) } \\
\text { Çeşit }\end{array}$} & \multirow{2}{*}{$\begin{array}{c}\text { Tozlayıcı } \\
\text { (Baba) Çeşit }\end{array}$} & \multicolumn{2}{|c|}{ Salkım Sayısı } & \multicolumn{3}{|c|}{ Çekirdek Sayısı } & \multirow[b]{2}{*}{$\begin{array}{c}\text { Canlılık } \\
(\%)^{*}\end{array}$} \\
\hline & & & $\begin{array}{l}\text { Emaskule } \\
\text { Edilen }\end{array}$ & $\begin{array}{c}\text { Hasat } \\
\text { Öncesi }\end{array}$ & $\begin{array}{c}\text { Canlı } \\
\text { (Suda } \\
\text { Batan) }\end{array}$ & $\begin{array}{c}\text { Zayıf } \\
\text { (Suda } \\
\text { Yüzen) }\end{array}$ & $\begin{array}{c}\text { Salkım } \\
\text { başına } \\
\text { (ortalama) }\end{array}$ & \\
\hline 1 & Kyoho & $\begin{array}{l}\text { Kishmish } \\
\text { Vatkana }\end{array}$ & 5 & 4 & 4 & 20 & $2 .-0.07$ & $17 \mathrm{p}$ \\
\hline 2 & Kyoho & $\begin{array}{l}\text { Crimson } \\
\text { Seedless }\end{array}$ & 5 & 2 & 5 & 45 & 25 & $10^{\mathrm{r}}$ \\
\hline 3 & Kyoho & $\begin{array}{l}\text { Superior } \\
\text { Seedless } \\
\end{array}$ & 6 & 4 & 6 & 33 & 10 & $15^{q}$ \\
\hline 4 & Atasarısı & Autumn Royal & 3 & 2 & 0 & 1 & 0,5 & $0^{\mathrm{t}}$ \\
\hline 5 & Atasarisı & $\begin{array}{c}\text { Yalova } \\
\text { Çekirdeksizi }\end{array}$ & 4 & 3 & 6 & 8 & 5 & $43^{j}$ \\
\hline 6 & Atasarısı & $\begin{array}{l}\text { Crimson } \\
\text { Seedless } \\
\end{array}$ & 4 & 3 & 23 & 4 & 9 & $85^{\mathrm{a}}$ \\
\hline 7 & Atasarısı & Kismish Vatkana & 4 & 1 & 4 & 1 & 5 & $80^{\mathrm{d}}$ \\
\hline 8 & $\begin{array}{l}\text { Yalova } \\
\text { Beyazı }\end{array}$ & $\begin{array}{c}\text { Samancl } \\
\text { Çekirdeksizi }\end{array}$ & 3 & 3 & 2 & 2 & 1 & $50^{\mathrm{h}}$ \\
\hline 9 & $\begin{array}{l}\text { Yalova } \\
\text { Beyazı }\end{array}$ & Fantasy Seedless & 2 & 2 & 3 & 3 & 3 & $50^{\mathrm{h}}$ \\
\hline 10 & Köfteci & Kismish Vatkana & 5 & 5 & 34 & 69 & 21 & $33^{1}$ \\
\hline 11 & Köfteci & $\begin{array}{l}\text { Crimson } \\
\text { Seedless } \\
\end{array}$ & 3 & 3 & 161 & 180 & 114 & $47^{i}$ \\
\hline 12 & Köfteci & $\begin{array}{l}\text { Superior } \\
\text { Seedless } \\
\end{array}$ & 3 & 3 & 80 & 37 & 39 & $68^{f}$ \\
\hline 13 & Köfteci & Autumn Royal & 4 & 4 & 27 & 254 & 70 & $10^{\mathrm{r}}$ \\
\hline 14 & Köfteci & $\begin{array}{c}\text { Samancl } \\
\text { Çekirdeksizi } \\
\end{array}$ & 2 & 2 & 107 & 24 & 66 & $82^{c}$ \\
\hline 15 & Köfteci & Fantasy Seedless & 2 & 2 & 20 & 8 & 14 & $71^{\mathrm{e}}$ \\
\hline 16 & Köfteci & $\begin{array}{c}\text { Yalova } \\
\text { Çekirdeksizi } \\
\end{array}$ & 2 & 2 & 65 & 130 & 98 & $33^{1}$ \\
\hline 17 & Köfteci & Bronx seedless & 1 & 1 & 40 & 63 & 103 & $39 \mathrm{k}$ \\
\hline 18 & Beyaz Çavuş & Kismish Vatkana & 5 & 5 & 134 & 115 & 50 & $54 \mathrm{~g}$ \\
\hline 19 & Beyaz Çavuş & $\begin{array}{l}\text { Crimson } \\
\text { Seedless } \\
\end{array}$ & 6 & 6 & 190 & 702 & 149 & $2^{\circ}$ \\
\hline 20 & Beyaz Çavuş & $\begin{array}{c}\text { Ergin } \\
\text { Çekirdeksizi }\end{array}$ & 6 & 6 & 164 & 412 & 96 & $28^{\mathrm{m}}$ \\
\hline 21 & Beyaz Çavuș & Autumn Royal & 4 & 4 & 9 & 154 & 41 & $6^{s}$ \\
\hline 22 & Beyaz Çavuş & $\begin{array}{c}\text { Yalova } \\
\text { Çekirdeksizi } \\
\end{array}$ & 10 & 10 & 237 & 685 & 92 & $26^{n}$ \\
\hline 23 & Red Globe & Kismish Vatkana & 5 & 4 & 99 & 17 & 29 & $85^{\mathrm{a}}$ \\
\hline 24 & Red Globe & $\begin{array}{l}\text { Crimson } \\
\text { Seedless } \\
\end{array}$ & 5 & 5 & 88 & 17 & 21 & $84^{b}$ \\
\hline TOPLAM & & & 99 & 86 & 1508 & 2984 & 52 & 34 \\
\hline
\end{tabular}

*Farklı harfle adlandırılan uygulamalar arasında istatistik olarak anlamlı bir fark vardır $(\mathrm{p}<0.05)$ 
Salkım başına düşen çekirdek sayısı bakımından Crimson Seedless (baba) X Beyaz Çavuș (ana) olarak kullanıldığı kombinasyonun en fazla sayısı melez çekirdek verdiği görülmüștür. Salkım bașına canlı çekirdek sayısı bakımından ise en başarılı kombinasyonlar ise Crimson Seedless (baba) X Köfteci üzümü (ana) ve Samancı Çekirdeksizi (baba) X Köfteci Üzümü (ana) kombinasyonları olmuştur. Özellikle Beyaz Çavuşun ana olarak kullanıldığı kombinasyonlarda çok sayıda çekirdek elde edilmesine karşılık canlılık oranlarının Red Globe ve Köfteci üzümü'nün ana olarak kullanıldığı kombinasyonlara göre daha düşük olduğu görülmüştür.

Çizelge 3. Kombinasyonlardaki herbir ebeveyne ait $\%$ canlılık oranları

\begin{tabular}{ccc}
\hline & Ebevenler & $\begin{array}{c}\text { Kombinasyon canlılık } \\
\text { ortalamaları (\%) }\end{array}$ \\
\hline & Kishmish Vatkana & 54 \\
Baba & Crimson Seedless & 41 \\
olarak & Superior Seedless & 42 \\
kullanılan & Autumn Royal & 5 \\
çeşitler & Yalova Çekirdeksizi & 34 \\
& Ergin Çekirdeksizi & 28 \\
& Samancı Çekirdeksizi & 66 \\
Fantasy Seedless & 71 \\
Ana & Bronx Seedless & 39 \\
olarak & Red Globe & 85 \\
kullanılan & Köfteci Üzümü & 48 \\
çeşitler & Kyoho & 14 \\
& Beyaz Çavuş & 27 \\
& Yalova Beyazı & 50 \\
\hline
\end{tabular}

$\mathrm{Bu}$ çalışmadan elde edilen sonuçlardan da anlaşılacağı üzere tozlayıcı çeşit seçimi ıslah çalışmalarında melez tohumlarda canlılık oranı ve sonuçta başarıyı önemli oranda etkileyebilmektedir. Yapılan benzer çalışmalarda da özellikle seçilen tozlayıcı çeşitlerin ve tozlanma şeklinin ıslah çalışmalarında başarıyı etkiledikleri bildirilmektedir (Marasalı ve Ergül, 1997; Şahin ve Sabır, 2016).

\section{Sonuç ve Öneriler}

Son yıllarda yeni sofralık üzüm çeşitlerinin elde edilmesi amacıyla yürütülen ıslah çalışmalarında hastalıklara dayanıklılık, çekirdeksizlik, iri tane ve kendine has aroma en bașta gelen özellikler arasındadır. Bu amaçla farklı kromozom sayısına sahip çeşitler ile türlerarası melezlemeler büyük önem kazanmıştır. Ancak bu çalışmalarda başarılı sonuçlar almak için uygun kombinasyonların belirlenmesi gerekmektedir. $\mathrm{Bu}$ çalışmada da sıralanan özellikleri tașıyan yeni melez genotiplerin eldesi amacıyla kurgulanan bir ıslah çalışmasında farklı kombinasyonlar içerisinden canlılık oranı en yüksek olanların belirlenmesi hedeflenmiştir.

Çalışmamız sonucunda özellikle Red Globe, Köfteci ve Beyaz Çavuş çeșitlerinin ana olarak kullanıldığı kombinasyonlar diğerlerine göre ön plana çıkmıștır. $\mathrm{Bu}$ çeşitler hemen hemen tüm çekirdeksiz çeşitlerle melezlendiği kombinasyonlarda hem çekirdek sayısı hem de canlılığı bakımından diğer kombinasyonlara göre daha iyi sonuç vermiştir. Sonraki yıllarda yapılacak melezleme çalışmalarında ağırlıklı olarak bu kombinasyonların kullanılması planlanmakta olup ayrıca sofralık üzüm ıslahına girmeyi düșünen araştırmacılara da bu yönde tavsiyede bulunulacaktır.

\section{Teșekkür}

$\mathrm{Bu}$ araştırma Yalova Atatürk Bahçe Kültürleri Merkez Araştırma Enstitüsü ve Kore Cumhuriyeti Gyeongsangbuk-Do Tarımsal Araştırma ve Yayım Hizmetleri arasında ortak yürütülen proje ile desteklenmiştir.

\section{Kaynaklar}

Akkurt, M., Keskin, N., Shidfar, M., Çakır, A. 2013. Effects of Some Treatments Prior to Stratification on Germination in Kalecik Karası (Vitis vinifera L.) Seeds. Iğdır Univ. J. Inst. Sci. \& Tech., 3 (4): 9-13.

Altıntoprak, O., Ağaoğlu, Y.S., 1999. Vinifera x Amerikan melezi asma çekirdeklerinin çimlenme yetenekleri üzerinde bir araştırma. Türkiye III. Ulusal Bahçe Bitkileri Kongresi (14-17 Eylül 1999, Ankara) Bildirileri 979-982.

Anonim, 1982. Bağcllıkta Melezleme Yoluyla Islah Çalışmaları, Bağcılık Araștırma Enstitüsü, Tekirdağ.

Cadot, Y., Minana-Castello, T.M., Chevalier, M., 2006. Anatomical, histological, and histochemical changes in grape seeds from Vitis vinifera $\mathrm{L}$. cv Cabernet franc during fruit development. Journal of Agricultural and Food Chemistry 54: 9206-9215.

Çelik, S., 1998. Bağcılık (Ampeloloji) Kitabı (Cilt: 1). Namık Kemal Üniversitesi Ziraat Fakültesi Bahçe Bitkileri Bölümü, Tekirdağ $425 \mathrm{~s}$.

Çetinbaş, M., Koyuncu, F., 2005. Soğukta nemli katlama ve tohum kabuğunun kuş kirazı (Prunus avium L.) tohumlarında dormansinin kırılması üzerine etkileri. Akdeniz Üniversitesi Ziraat Fakültesi Dergisi, 18 (3): 417-423.

Dardeniz, A., Şeker, M., Yancar, A., Gökbayrak, Z., Bahar, E., Kahraman, K.A., 2011. Çanakkale'de Bozcaada üzüm çeşidi yetiştiriciliği ve karşılaşılan sorunlar. Uluslararası Katılımlı I. Ali Numan Kıraç Tarım 
Kongresi ve Fuarı, Eskișehir, 27-30 Nisan 2011, ss. 2567-2582.

Demirkaya, M., 2006. Polietilenglikol ile osmotik koşullandırma ve humidifikasyon uygulamalarının biber tohumlarının çimlenme hızı ve oranı üzerine etkileri. Erciyes Üniversitesi Fen Bilimleri Enstitüsü Dergisi, 22 (1-2): 223-228.

Downey, M. O., Harvey, J. S., Robinson, S. P., 2003. Analysis of tannins in seeds and skins of Shiraz grapes throughout berry development. Australian Journal of Grape and Wine Research 9 (1): 15-27.

Egli, D. B., 1998. Seed biology and the yield of grain crop; CAB International: Oxon, U.K. p 184.

Gülcan, R., İlter, E., 1975. Bağcılıkta Islah Metodları. Atatürk Bahçe Kültürleri Merkez Araștırma Enstitüsü Yayınları, Yalova.

Karataş, H., Ağaoğlu, Y.S., 2007. Bazı üzüm çeşitlerinin döl verimleri üzerine tozlayıcı Kalecik Karası çeşidinin etkileri. Tarım Bilimleri Dergisi, 13 (3): 261-264.

Karakurt, H., R. Aslantaş, A. Eşitken., 2010. Tohum çimlenmesi ve bitki büyümesi üzerinde etkili olan çevresel faktörler ve bazı ön uygulamalar. Uludağ Üniversitesi Ziraat Fakültesi Dergisi, 24 (2): 115128.

Kennedy, J. A., Troup, G. J., Pilbrow, J. R., Hutton, D. R., Hewitt, D., Hunter, C. R., Ristic, R., Iland, P. G., Jones, G. P., 2000. Development of seed polyphenols in berries from Vitis Vinifera L. cv. Shiraz. Australian Journal of Grape and Wine Research 6 (3): 244-254.

Lloreda De la Fuente, M., 2018. Use of hybrids in viticulture. A challenge for the OIV. OENO One, 52 (3): 231-234.

Li, G.R., Ji, W., Wang, G., Zhang, J.X., Wang, Y.J., 2014. An improved embryo-rescue protocol for hybrid progeny from seedless Vitis vinifera grapes $\times$ wild Chinese Vitis species. In Vitro Cellular and Developmental Biology-Plant 50: 110.

Marasalı, B., Ergül, A., 1997. Farklı tozlanma şekillerinin üzüm çeşitlerinde tane tutumu ve çekirdek oluşuna etkileri. Tarım Bilimleri Dergisi, 3 (1): 39-42.

Mullins, M. G., Bouquet, A., Williams, L. E., 1992, Biology of the Grapevine, Cambridge University Press, p. 239.
Orhan Özalp, Z., Ergönül, O., 2013. Asma ıslahında poliploidi çalışmaları. Namık Kemal University Journal of Natural Sciences, 14 (2): 103-107.

Perl, A., Sahar, N., Spiegel-Roy, P., Gavish, S., Elyası, R., Orr, E., Bazak, H., 2000. Conventional and Biotechnological Approaches in Breeding Seedless Table Grapes. Acta Horticulturae 528: 613-618.

Sabır, A., 2015. Xenia and metaxenia in grapes: differences in berry and seed characteristics of maternal grape cv. 'Narince' (Vitis vinifera L.) as influenced by different pollen sources, Plant Biology, 17 (2): 567 573.

SAS Institute, 2007. JMP Statistical Discovery Software. JMP 7.0 Edition of Program. Cary, NC, USA: SAS Institute.

Şahin, G., 2016. Farklı tozlayıcıların Alphonse Lavallée (V. vinifera $\mathrm{L}$.) Üzüm çeşidinde tane tutumu ile tane ve çekirdek özellikleri üzerine etkileri. Selçuk Üniversitesi Fen Bilimleri Enstitüsü Yüksek Lisans Tezi. Konya, $41 \mathrm{~s}$.

Şahin, G., Sabır, A., 2016. Farklı polen kaynakları ile tozlanan Alphonse Lavallée üzüm çeșidinde tane büyüme seyri ve tane şekil indeksi. Bahri Dağdaş Bitkisel Araştırma Dergisi 5 (1): 7-13.

Tian, L., Wang, Y, Niu, Y., Tang, D., 2008. Breeding of disease-resistant seedless grapes using Chinese wild Vitis spp. I. In Vitro Embryo Rescue and Plant Development. Scientia Horticulturae 117: 136-141.

Uysal, H., Can Ağırbaş, N., Saner, G., 2016. Türkiye'de sofralık üzüm dıșsatımına ilișkin temel yaklașımlar ve hedefler. Tarım Ekonomisi Dergisi 22 (1): 11-17.

Wakana, A., Hiramatsu, M., Park, S.M., Hanada, N., Fukudome, I., Yasukochi, K., 2003. Seed abortion in cross between diploid and tetraploid grapes (Vitis vinifera and V.complex) recovery of triploid plants through embryo culture. Journal of Faculty of Agriculture Kyushu Univercity, 48 (1-2): 39-50.

Winkler A.J., Cook, J.A., Klewer, W.M., Lider, L.A., 1974. General Viticulture, Univercity of California Press. Berkeley, Los Angeles.

Zohary, D., Hopf, M., 2000. The domestication of the plants in the old world: The origin and spread of cultivated plants in West Asia, Europe and Nile valley, 3rd edn. Oxford University Press, Oxford. 